\title{
Development of the Stent for Nephroamniotic Shunting
}

\author{
${ }^{1}$ Natalia V Kosovtsova, ${ }^{2}$ Nadezhda V Bashmakova, ${ }^{3}$ Mariia V Pavlichenko, ${ }^{4}$ Tatiana V Markova \\ ${ }^{5}$ Natalia P Shabunina-Basok, ${ }^{6}$ Kira A Izmestieva
}

\section{ABSTRACT}

Early prenatal diagnosis and timely prenatal and postnatal surgery prevent complications and unfavorable outcomes of the urinary system disorders in newborns in most cases.

One option for the correction of obstructive uropathy is stenting fetal urinary tract. Shunting the bladder is used abroad; we have experience of nephroamniotic shunting of fetal kidneys. This fetal surgery is carried out in order to preserve renal parenchyma with obstructive uropathy.

Keywords: Congenital malformations of the fetus, Minimally invasive surgery, Morphological methods, Obstructive uropathy, Pregnancy, Renal stenting, Stent.

How to cite this article: Kosovtsova NV, Bashmakova NV, Pavlichenko MV, Markova TV, Shabunina-Basok NP, Izmestieva KA. Development of the Stent for Nephroamniotic Shunting. Donald School J Ultrasound Obstet Gynecol 2018;12(1):13-16.

\section{Source of support: Nil}

Conflict of interest: None

\section{INTRODUCTION}

Recent epidemiological studies suggest that the incidence of diseases of the urinary system among children ranges

\footnotetext{
1,5 Head, ${ }^{2}$ Director, ${ }^{3,4}$ Senior Researcher, ${ }^{6}$ Junior Researcher

${ }^{1}$ Department of Biophysical and Radiation Research Methods FGBU Mother and Child Care Research Institute, Ministry of Health of the Russian Federation, Yekaterinburg, Russia

${ }^{2}$ FGBU Mother and Child Care Research Institute, Ministry of Health of the Russian Federation, Yekaterinburg, Russia

${ }^{3}$ Department of Children of Early Age, FGBU Mother and Child Care Research Institute, Ministry of Health of the Russian Federation, Yekaterinburg, Russia

${ }^{4}$ Department of Fetal Antenatal Care, FGBU Mother and Child Care Research Institute, Ministry of Health of the Russian Federation, Yekaterinburg, Russia

${ }^{5}$ Department of Pathomorphology and Cytodiagnostics, FGBU Mother and Child Care Research Institute, Ministry of Health of the Russian Federation, Yekaterinburg, Russia

${ }^{6}$ Department of Pathomorphology and Cytodiagnostics, FGBU Mother and Child Care Research Institute, Ministry of Health of the Russian Federation, Yekaterinburg, Russia

Corresponding Author: Natalia V Kosovtsova, Head Department of Biophysical and Radiation Research Methods FGBU Mother and Child Care Research Institute, Ministry of Health of the Russian Federation, Yekaterinburg, Russia, e-mail: kosovcovan@mail.ru
}

from 5.4 to $34.2 \%$, and it is different in various groups of children, and the highest (74\%) is in the group of children who were born in families with nephropathy. ${ }^{1-15}$

If the severe congenital malformation of the urinary system is detected, the issue of abortion up to 22 weeks of pregnancy is discussed with the family. Scientific research studies show that the preconditions for the development of chronic kidney and distal urinary system diseases in infants and older are formed in the peri- and neonatal periods. In modern conditions, if we master the methods of prenatal correction of obstructive uropathy, we can improve the perinatal outcomes in severe bilateral and unilateral disorders of the urinary system.

The research and development of fetal surgery methods allow to drain the urinary system.

Most frequently, there is installed vesicoamniotic shunt in case of posterior urethral valve disorder and urethral atresia. A multicenter randomized controlled research [Percutaneous shunting for Lower Urinary Tract Obstruction (PLUTO)] was conducted in Europe in 2007, and proved that the prenatal vesicoamniotic shunting improves kidney function and eventually perinatal outcomes. However, until now, this question is controversial; the study of urinary tract obstruction process in the fetus and the mechanisms of its effect on nephrogenesis continues, and the more the information that will be published on the results of prenatal interventions, the better we will be presenting which patients need these interventions.

The FGBU Mother and Child Care Research Institute began to introduce methods of prenatal correction of obstructive uropathy by fetal renal stenting by nephroamniotic shunting because posterior urethral valve disorder combines with other obstructive uropathy often. Fetuses with bilateral hydronephrosis grade III to IV as well as posterior urethral valve disorder have an unfavorable prognosis for newborn life and health, and also have indications for intrauterine correction.

The purpose of the study is approbation of our new developed stent $3 \mathrm{Fr}, 5 \mathrm{~cm}$, with original pigtails for intrauterine shunting of the kidneys in experimental animals (sheep).

\section{MATERIALS AND METHODS}

The new stent testing was taken in 10 sheep in the period between 75 and 98 days of singleton pregnancy. The first five sheep were installed the our new stent $3 \mathrm{Fr}, 5 \mathrm{~cm}$, 
Fig. 1: Photograph of the assembled introducer

with original pigtails, and another five were installed with "Cook" company neonatal stent, $3 \mathrm{Fr}, 10 \mathrm{~cm}$ as a control group. According to our research, expulsion of the "Cook" company stent occurred, in contrast to the new stent, which was developed at FGBU Mother and Child Care Research Institute. Morphometric analysis of experimental animal fetal kidneys after prenatal stenting proves the safety of using this nephroamniotic stent.

The study was performed at the FGBU Mother and Child Care Research Institute. Silicone rubber compound MC Series and MS-R-STP MS No 1-93 were selected as material for our stents. This material was chosen because it is already used for the manufacture of similar purpose and passed all necessary tests. As already mentioned, the dimensions of all stent elements must be precisely aligned with each other; therefore, we used the silicone tube with an outer diameter of $1.05 \pm 0.03 \mathrm{~mm}$ and an inner diameter of $0.55 \pm 0.03 \mathrm{~mm}$ for manufacturing stents.

The mechanical characteristics of stents must comply with specifications 9398-041-18037666-2005, while the tensile strength of stents should be at least $6 \mathrm{H}$. Stents should not be straightened in a free state. The conductor should pass freely inside the stent.

Testing of different "curls" shapes and sizes was carried out on the simulator "Simulab" production of BOSS Instruments Ltd. and we evaluated the efficiency of the stent fixation element in the working position (e.g., "curl"). The best indicators were shown by the fixation element "spiral". Thus, it was chosen as the main.

Renal stenting by the new modified stent $3 \mathrm{Fr}, 5 \mathrm{~cm}$, with original pigtails was conducted in five pregnant sheep.

The complex of research methods applied in the morphological study of the experimental animal kidneys includes: Organometry, overview microscopy of the slide mounts, and morphometry.

The results obtained at all stages of the research were introduced into the electronic database and subjected to statistical processing. Using the methods of descriptive statistics, the median and standard deviation of quantitative parameters were determined. Determination of reliability of parameters between the groups was carried out by the Mann-Whitney U-test. Correlation analysis of the definition of the nonparametric Spearman's rank correlation coefficient revealed a correlation between several parameters in the groups and its validity.
Fig. 2: Sharpening trocar and stylet

The study of structural components in the renal tissue slide mounts was conducted using a "Axio Scope A1" microscope, which was equipped with a digital camera "Axio Cam 5S" (Carl Zeiss, Germany) with a zoom-in (a $10 \mathrm{~mm}$ eyepiece, a $20 \mathrm{~mm}$ lens), using the "AxioVision" 4.8.2 computer program (Carl Zeiss, Germany).

\section{RESULTS}

The technical project and thermostatic technology to form the stent with the desired size and shape were developed. The installation kit of the stent includes:

The Introducer (a device for introducing the stent into the kidney) is a device consisting of a trocar and stylet. In the design, it was necessary to select the type and optimum sharpening angles stylet and stylet handle dimensions (Figs 1 and 2).

The Conductor is used for holding the stent through the trocar into the work area. The diameter of the conductor must be somewhat smaller than the inner diameter of the stent in order to move it freely through the conductor.

The Ekstruzor serves to move the stent on the conductor through the trocar into the workspace. In contrast to known analogs, it is advisable to make ekstruzor of a metal tube, providing it with a handle in the form of a thickened portion to facilitate the procedure of "pushing" the stent through the trocar (Fig. 3).

The tool kit for prenatal stenting was sterilized and placed in a sterile packaging. It includes a stent introducer, conductor, and ekstruzor.

\section{Demonstration Stages of the Introduction and Deployment of the Stent in the Simulator}

Extract from the sterile packaging stent prosthesis (Fig. 4) and check its integrity.

Extract from the sterile packaging sheath and enter it into the workspace. In practice, this is done under ultrasound control. Remove the obturator after that. Fix the introducer in the operating position of the free hand fingers. Then introduce the conductor with the stent into

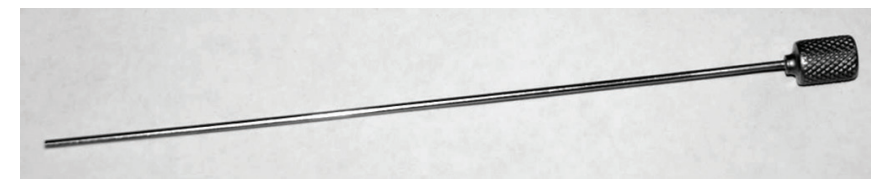

Fig. 3: Ekstruzor 




Fig. 4: Full view of the stent

the tube introducer. Ekstruzor pushes the stent in the work area, pigtail spiral wraps, ensuring its fixation in the body. The sheath is removed, and the stent is in position. The second pigtail restricts the movement of the stent on the outside (Fig. 5).

A utility model (renal stent No 152166) patent was received on December 10, 2014. Authors: Kosovtsova, Bashmakova, Markova. After the registration of the medical device, we are going to apply our stent in clinical practice.

\section{EXPERIMENTAL PART}

Our newly developed stent $3 \mathrm{Fr}, 5 \mathrm{~cm}$, with original pigtails was installed in five experimental animals (main group) for testing. The total number of objects of study was 10 lambs including 5 (control group) which were introduced with Cook company neonatal stent, $3 \mathrm{Fr}, 10 \mathrm{~cm}$ with the duration of intrauterine life from 75 to 98 days.

Under the ultrasound control (Voluson E8 GI), our newly developed stent $3 \mathrm{Fr}, 5 \mathrm{~cm}$, with original pigtails at FGBU Mother and Child Care Research Institute was installed into the kidney of sheep fetus from the main group (while Cook company stent was installed into the kidney of sheep fetus from the control group). All the sheep were brought back to the farm after the stenting. A month later, after the slaughter of sheep, fetuses were

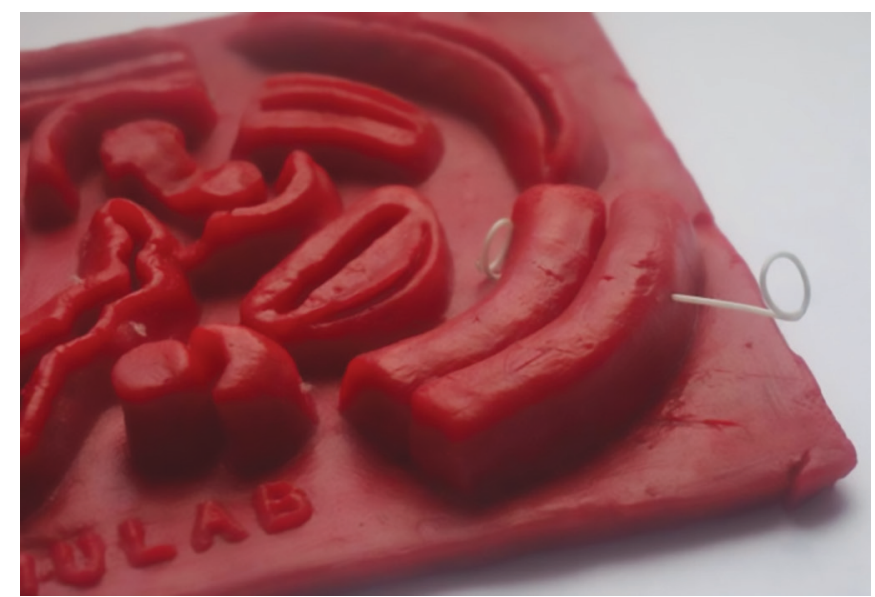

Fig. 5: The Introducer was removed and the stent is in the operating position delivered at FGBU Mother and Child Care Research Institute. Fetal autopsy and pathological examination of stented and contralateral kidney were conducted (Fig. 6).

For comparison, the control group was formed with the fetuses of sheep which were installed with the standard stents-Cook company neonatal stents 3.0 Fr, 10 mm. A spinal needle G16 "B-Braun" (with a rounded end) was used as a guide. Three miscarriages were reported in the control group, fetuses were delivered for autopsy at FGBU Mother and Child Care Research Institute, and stent expulsion was observed in all five fetuses from the control group.

According to the results of the morphological study of the experimental animal kidneys with all stents we found during the experiment:

- Slight focal sclerotic lesions in the renal capsule at the overview microscopic examination of the tissue slide mounts of the fetal kidneys, which were introduced with our stent.

- Minimal inflammatory infiltration in the capsule fibrosis: from single to 10 cells in the visual field $(\times 200)$.

- Inflammatory infiltration of cells, such as: lymphocytes, plasma cells, histiocytes, and neutrophils.

- The absence of inflammatory and sclerotic lesions in the renal parenchyma in the area around the stent in most cases of this group (4).

- Lobular inflammatory infiltration of cells, such as neutrophils, lymphocytes, and plasma cells in the renal medulla in one case (1); damaged nephron structure was absent at the perifocal area and at a distance from the inflammatory center.

Thus, it was proved that:

- The presence of a foreign body (stent) in the renal parenchyma does not cause organ changes.

- A long (up to 1 month) interposition of our stent in the kidney morphological signs of inflammatory

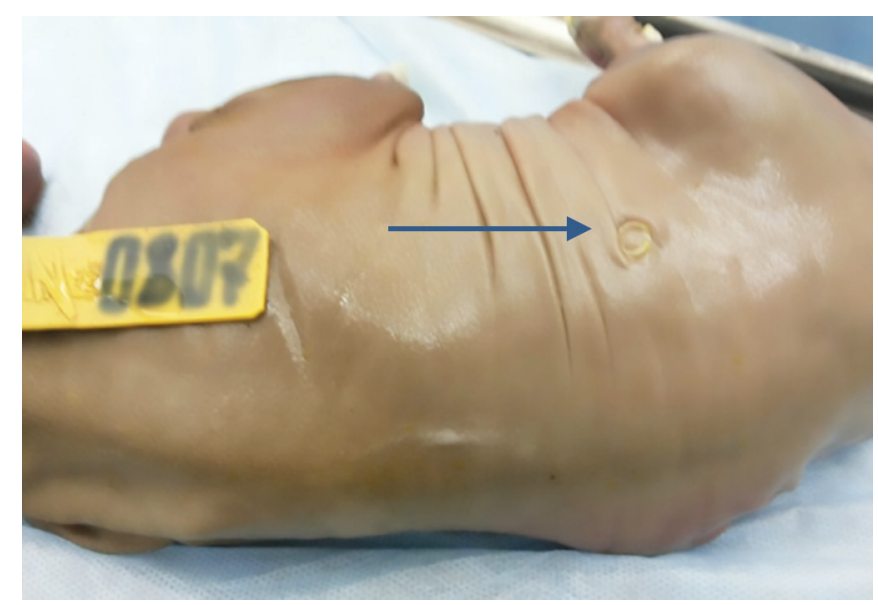

Fig. 6: The stent is in the fetal kidney 
infiltration and tissue reparation form in the renal capsule only. Inflammatory changes in the renal parenchyma are absent in most cases $(80 \%)$. Sclerotic lesions of the renal parenchyma were not found.

- Various times of the stent interposition in the body tissues cause the "compression" damage to the renal parenchyma to a variable degree. Regardless of this, significant damage to renal medulla is not identified.

\section{CONCLUSION}

Our newly developed stent $3 \mathrm{Fr}, 5 \mathrm{~cm}$, with original pigtails testing for intrauterine shunting of the kidneys in experimental animals (sheep) showed a high reliability and safety in its use as evidenced by morphometric picture.

\section{REFERENCES}

1. Pluto Collaborative Study Group, Kilby M, Khan K, Morris K, Daniels J, Gray R, Magill L Martin B, Thompson P, Alfirevic Z, et al. PLUTO trial protocol: percutaneous shunting for lower urinary tract obstruction randomised controlled trial. BJOG 2007 Jul;114(7):904-905, e1-e4.

2. Wu S, Johnson MP. Fetal lower urinary tract obstruction. Clin Perinatol 2009 Jun;36(2):377-390.

3. KosovtsovaNV, Bashmakova NV, PavlichenkoMN, MarkovaTV. A new look at the treatment of obstructive uropathies in the fetus. Quest Gynecol Obstet Perinatol 2015;14(3):33-38.

4. Kosovtsova NV, Bashmakova NV, Pavlichenko MV, Markova TV. Outcome of prenatal interventions for fetal lower urinary tract obstruction. Sci World Int Sci J 2015 Aug;9(25):109-117.

5. Kosovtsova NV, Markova TV, Kovalev VV, Potapov NN. The case of intrauterine correction of infravesical obstruction. Ural Med J (Perinatol) 2012; 11(103):36-38.
6. Morris RK, Middleton LJ, Malin GL, Quinlan-Jones E, Daniels J, Khan KS, Deeks J, Kilby MD; PLUTO Collaborative Group. Outcome in fetal lower urinary tract obstruction: a prospective registry study. Ultrasound Obstet Gynecol 2015 Oct;46(4):424-431.

7. Malin G, Tonks AM, Morris RK, Gardosi J, Kilby MD. Congenital lower urinary tract obstruction: a population-based epidemiological study. BJOG 2012 Nov;119(12):1455-1464.

8. Ruano R, Yoshizaki CT, Giron AM, Srougi M, Zugaib M. Cystoscopic placement of transurethral stent in a fetus with urethral stenosis. Ultrasound Obstet Gynecol 2014 Aug;44(2):238-240.

9. Won HS, Kim SK, Shim JY, Lee PR, Kim A. Vesicoamniotic shunting using a double-basket catheter appears effective in treating fetal bladder outlet obstruction. Acta Obstet Gynecol Scand 2006 Feb;85(7):879-884.

10. Bernardes LS, Aksnes G, Saada J, Masse V, Elie C, Dumez Y, Lortat-Jacob SL, Benachi A. Keyhole sign: how specific is it for the diagnosis of posterior urethral valves? Ultrasound Obstet Gynecol 2009 Oct;34(4):419-423.

11. Morris RK, Ruano R, Kilby MD. Effectiveness of fetal cystoscopy as a diagnostic and therapeutic intervention for lower urinary tract obstruction: a systematic review. Ultrasound Obstet Gynecol 2011 Jun;37(6):629-637.

12. Welsh A, Agarwal S, Kumar S, Smith RP, Fisk NM. Fetal cystoscopy in the management of fetal obstructive uropathy: experience in a single European center. Prenat Diagn 2003 Dec;23(13):1033-1041.

13. Robyr R, Benachi A, Daikha-Dahmane F, Martinovich J, Dumez Y, Ville Y. Correlation between ultrasound and anatomical findings in fetuses with lower urinary tract obstruction in the first half of pregnancy. Ultrasound Obstet Gynecol 2005 May;25(5):478-482.

14. Kosovtsova NV. Intrauterine surgical interventions under the ultrasound supervision are no longer fiction. Med Urals Chelyabinsk 2011;3:C14-C16.

15. Khalafyan AA. STATISTICA 6.0 Statistical analysis of data, 3rd ed. Network Resource http://rutracerorg/forum/viemtopic/ pht?T/1674500. 